\section{Acute liver failure as the first manifestation of very late relapsing of Hodgkin's disease}

\author{
Xavier Ortín, ${ }^{1}$ Marta Rodríguez-Luaces, ${ }^{1}$ \\ Ramon Bosch, ${ }^{2}$ Marylene Lejeune, ${ }^{2}$ \\ Llorenç Font ${ }^{1}$ \\ 'Servicio de Hematología, Hospital de \\ Tortosa Verge de la Cinta, Tortosa, Spain; \\ 2Servicio de Anatomía Patológica, \\ Hospital de Tortosa Verge de la Cinta, \\ Tortosa, Spain
}

\section{Abstract}

Hodgkin's disease is, in general, a lymph node-based disease. It usually starts in an area within the lymphatic system and spreads, in an orderly manner, along the lymphatic chain to contiguous lymph node areas. There have been sporadic case reports of acute liver failure caused by hematological malignancies. Generally, liver failure is a feature of stage IV end-stage disease, when it occurs in lymphoma. Thus, hepatic involvement usually occurs late in the course of Hodgkin's disease or with advanced-stage disease, and primary presentation in the liver with acute liver failure is extremely rare. In most cases, the diagnosis was made at autopsy. We describe a patient with Hodgkin's disease presenting with acute liver failure. This is a very unusual Hodgkin's disease form of presentation, because the acute liver failure was the presenting feature of the disease. Furthermore, the lymphoma occurred as a very late relapse, twenty years after the first diagnosis. To the best of our knowledge, such a case has not been described to date.

\section{Case Report}

A 59-year-old woman was diagnosed in May 1986 as suffering from stage IVA nodular sclerosis Hodgkin's disease (HD) with liver and spleen involvement. She received Mantel-like radiotherapy including submental, cervical, supra- and infraclavicular, axillary, hilar, and mediastinal lymph nodes. In October 1986, an exploratory laparotomy was performed, which showed retroperitoneal lymph node involvement and liver and splenic infiltration. Then, splenectomy and treatment with 12 cycles of CMOP/ABVD chemotherapy were performed. After finishing treatment, the presence of liver involvement (owing to the initial presence of infiltration of the liver) was re-evaluated.
Histological examination of the liver showed persistence of infiltration of HD. The patient was referred to another center where a second-line therapy with six courses of chemotherapy (CEP-CCNU, etoposide, and predmustine) was initiated. At the end of the treatment, the patient was in complete remission. She was controlled in the reference center during the ten years after the initial diagnosis, when she was considered cured of her disease. After this, there were no controls or subsequent additional scans done. In September 2009, the patient complained of asthenia, dyspnea, nocturnal sweats, and $39^{\circ} \mathrm{C}$ fever. She was admitted to hospital with jaundice.

The complete blood picture showed hemoglobin, $10.7 \mathrm{~g} / \mathrm{dL}$; platelet count, $305 \times 10^{9} / \mathrm{L}$; and leukocyte count, $8.6 \times 10^{9} / \mathrm{L}$. Serum biochemistry showed total protein, $5.3 \mathrm{~g} / \mathrm{dL}$ (reference values: $6.0-8.0 \mathrm{~g} / \mathrm{dL}$ ); albumin, 1.8 $\mathrm{g} / \mathrm{dL}$ (reference values: $3.5-4.6 \mathrm{~g} / \mathrm{dL}$ ); alkaline phosphatise, $1257 \mathrm{U} / \mathrm{L}$ (reference values: 70 $270 \mathrm{UI} / \mathrm{L}$ ); ferritine, $4207 \mathrm{ng} / \mathrm{mL}$ (reference values: $24-336 \mathrm{ng} / \mathrm{mL}$ ). Liver enzymes and bilirubin were significantly elevated: total bilirubin, $4.0 \mathrm{mg} / \mathrm{dL}$ (reference values: 0.2 $1.2 \mathrm{mg} / \mathrm{dL}$;); direct, $2.4 \mathrm{mg} / \mathrm{dL}$ (normal value: $<0.3 \mathrm{mg} / \mathrm{dL}$ ); GOT, $76 \mathrm{UL} / \mathrm{L}$ (reference values 5-37 UI/L); GPT, 74 UI/L (reference values: 5$40 \mathrm{UI} / \mathrm{L}$ ); gamma-GT, $327 \mathrm{UI} / \mathrm{L}$ (reference values 5-50 UI/L). Serum $\alpha$-fetoprotein and carcino-embryonic antigen levels were within normal limits. Serology for HIV and hepatitis $\mathrm{B}$ and $\mathrm{C}$ were negative. Serology for CMV and EBV were IgM-negative and IgG-positive. Repeat blood cultures and sepsis work-up did not reveal any focus of infection.

A body computer tomography (CT) scan showed retroperitoneal enlarged lymph glands, without focal liver lesions or other lymphadenopathies. The study was extended by a PET-CT scan. It showed, in addition to the lymph nodes, a liver hypermetabolic lesion in the right lobe, segment VIII, suggestive of malignancy. A liver needle biopsy was performed. The histological examination of the liver showed portal and porto-portal fibrous septa and atypical large mononuclear Hodgkin's cells and typical ReedSternberg (RS) cells CD30+ CD15+, LMP CD $45^{-}$(Figure 1). Bone marrow was also affected.

The diagnosis of a very late relapse of HD with liver involvement was made and the ABVD protocol (Adriamycin-bleomycin-vinblastine-dacarbazine) was given. Two days after chemotherapy, the patient's general condition progressively deteriorated with massive pleural effusion, renal failure, and acute liver failure with hepatic encephalopathy. The patient died in spite of being moved to the intensive care unit. The family refused a postmortem examination.
Correspondence: Xavier Ortín, Servicio de Hematología, Hospital de Tortosa Verge de la Cinta, C/Esplanetes s/n, 43500 Tortosa, Spain.

E-mail: xavi.ortin@gmail.com

Key words: acute liver failure, Hodgkin’s disease.

Received for publication: 25 March 2010.

Revision received: 15 July 2010.

Accepted for publication: 15 July 2010 .

This work is licensed under a Creative Commons Attribution 3.0 License (by-nc 3.0).

(C) Copyright X. Ortín et al., 2010

Licensee PAGEPress, Italy

Hematology Reports 2010; 2:e5

doi:10.4081/hr.2010.e5

\section{Discussion}

Hepatic involvement in HD usually occurs late in the course of the disease or with advanced-stage disease, and primary presentation in the liver is extremely rare..$^{1,3}$ Acute liver failure (ALF) can result from a wide variety of causes, of which viral and toxin-induced hepatitis are the most common. ALF also has been reported in patients with malignant infiltration of the liver by malignancies such as lung, breast, melanoma, and others. Hematological malignancies are the most common underlying etiology, including Hodgkin's lymphoma, non-Hodgkin's lymphoma, malignant histiocytosis, and leukemia. However, it is distinctly uncommon for ALF to be the initial manifestation of a malignant process. ${ }^{2-4}$

Hepatic infiltration by hematological malignancies occurs in $15-22 \%$ of cases, but very rarely causes ALF. A review showed that only 18 of 4020 patients (i.e. $0.44 \%$ ) admitted over a period of 18 years at a liver failure unit had ALF secondary to malignant infiltration. The etiology was HD in three patients. Most of the patients in this series had evidence of extrahepatic involvement of their disease, either with peripheral or intra-abdominal lymphadenopathy, bone marrow infiltration, or splenomegaly. ${ }^{2}$ Infiltrations by lymphoma of small intrahepatic bile ducts may result in extensive cholangitis, duct necrosis, and tumor obstruction of hepatic venules. On the other hand, tumor infiltrations of hepatic parenchyma may lead to a critical mass of hepatocyte destruction and subsequent ALF. Hepatic failure can occur even if cells had infiltrated extensively into the liver, and consequently hepatic failure and jaundice were considered the result of massive liver involvement. ${ }^{3,4}$

Making a diagnosis of hepatic infiltration in patients presenting with ALF in such cases generally is difficult, and hence HD can be diag- 


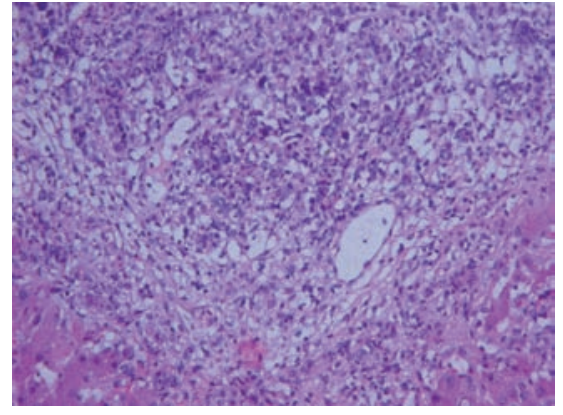

Figure 1. Portal infiltrate by Hodgkin's and pleomorphic Reed-Sterberg cells in the liver. (Hematoxylin-and-eosin stain; 200X magnification.)

nosed late. However, early diagnosis is very important because it is possible that quick institution of specific chemotherapy may reverse liver disease. Clinical and laboratory findings are not helpful for differential diagnosis. All of them may be seen in a number of primary liver diseases. Ultrasonography and CT scans seem to be inadequate in diagnosing hepatic lymphoma. ${ }^{4}$ To diagnose hepatic involvement, the presence of mononuclear variants of RS cells in an appropriate background is sufficient if the diagnosis of $\mathrm{HD}$ has been established in a lymph node, but if liver tissue is the only material examined, demonstration of classical multinucleated RS cells is required. ${ }^{1}$

As the liver has limited tolerance to radiotherapy, and surgery is only feasible for solitary lesions, the choice of treatment in this case with disseminated liver involvement was combined chemotherapy. ${ }^{1}$ Conventional-dose chemotherapy has demonstrated very poor results in refractory and early relapsed patients after first-line chemotherapy. For late relapsed patients (<12 months), salvage chemotherapy with conventional-dose therapy shows a $35 \%$ probability of overall survival (OS) five years after therapy. The remission rate is greatest in patients with late relapse ( $75 \%$ vs. $55 \%$ for early relapse vs. $35 \%$ for primary refractory Hodgkin's lymphoma).$^{6,7}$ Our case demonstrates that relapsing lymphoma in the liver, even in patients without evidence of extrahepatic malignancy, should be included in the differential diagnosis of ALF and treated accordingly. In the presence of lymphadenopathy and hepatomegaly in ALF patients, hematological malignancies should be taken into account, and liver and lymph node biopsies should be performed as early as possible. This is the only way to reach the correct diagnosis and start appropriate chemotherapy, which can be life-saving.

\section{References}

1. Chim CS, Choy C, Ooi CG, et al. Hodgkin's disease with primary manifestation in the liver. Leuk Lymphoma 2000;37:629-32.

2. Morali GA, Rozenmann E, Ashenazi J, et al. Acute liver failure as the sole manifestation of relapsing non-Hodgkin's lymphoma. Gastroenterol Hepatol 2001;13:1241-3.

3. Torneo C, Laparra E, Jiménez A, et al. Acute liver failure and Hodgkin's disease. An Med Interna 1998;15:654-5.

4. Vardareli E, Dündar E, Aslan V, et al. Acute liver failure due to Hodgkin's lymphoma. Med Princ Pract 2004;13:372-4.

5. Josting A, Franklin J, May M, et al. New prognostic score based on treatment outcome of patients with relapsed Hodgkin's lymphoma registered in the database of the German Hodgkin's Lymphoma Study Group. J Clin Oncol 2002;20:221-30.

6. Cavalieri E, Matturo A, Annechini G, et al. Efficacy of the BEACOPP regimen in refractory and relapsed Hodgkin lymphoma. Leuk Lymphoma 2009;50:1803-8.

7. Goodman KA, Riedel E, Serrano V, et al. Longterm effects of high-dose chemotherapy and radiation for relapsed and refractory Hodgkin's lymphoma. J Clin Oncol 2008;26: 5240-7. 